\title{
Classifying Personalization Constraints in Digital Business Environments through Case Study Research
}

\author{
Michael J. Harnisch \\ Institute of Information Science and Information Systems \\ University of Graz / evolaris next level GmbH \\ Graz, Austria
}

\begin{abstract}
To aid professionals in the early assessment of possible risks related to personalization activities in marketing as well as to give academics a starting point to discover not only the opportunities but also the risks of personalization, a 'Classification Scheme of Personalization Constraints' is established after the analysis of 24 case studies. The classification scheme includes three dimensions: origin (internal, external), subject (technological, organizational) and time (data collection, matchmaking, delivery) and describes the different obstacles with which companies are confronted when implementing personalization activities. Additionally four 'Standard Types of Personalization Environments' are developed. They describe a set of business environments which inherit different internal and external risks related to personalization activities in marketing. The standard types are termed Flow, Performance, Dependence and Risk.
\end{abstract}

Keywords-personalization; case study research; corporate communication; personalization constraint

\section{INTRODUCTION}

Developments in communication technology changed the communication patterns of customers and corporations. The traditional transfer of messages from person to person was redeemed by mass media communication which is nowadays more and more replaced by individualized respectively specified one-to-one-communication [1]. Additionally, an enormous amount of data and information is publicly available through the Internet, which is accessible through various stationary and mobile devices [2]. These developments equip customers with the ability to retrieve more information about a product or service much faster. But there are also downturns of these advances. Customers struggle with identifying relevant information which fit their personal preferences and needs [3]. Therefore companies need to implement certain actions in their corporate communication processes so that they communicate relevant marketing messages to their customers in an effective way. These actions could imply personalization activities, which include for example an individual adaption of customer touch points to the actual context or preferences of the customer, the provision of specific individualized messages or the collaborative-aided recommendation of similar products or services which the customer is looking for. By applying personalization activities on customer-related business processes, corporations are following a differentiation strategy [4-6]. This could yield additional value to the business by making communications more effective and as a result, raise for example conversion rates or buying intentions of the customers. Though, the application of personalization activities is subject to various limitations. For example, even if specialized tracking systems are employed, corporations are not always able to identify the context or the preferences of their customers. Businesses could also be confronted with legal constraints of implementing personalization activities (e.g. Opt-In requirements) or they suffer from elementary problems like privacy concerns or a lack of customer trust in personalization activities [7]. Research shows, that these constraints are able to significantly change the successful outcome of personalization activities.

Personalization is a very broad issue in research and ranges from computer sciences to social sciences. Although the influences of personalization constraints on the successful implementation of personalization activities and furthermore on the profit of businesses are apparent, only limited research has been published on the general theory of personalization constraints. A feasible explanation of this fact is the widespread possibilities of detailed research on personalization issues. Nevertheless, a classification scheme of personalization constraints is able to provide a first general overview of the various difficulties a company could come across while implementing personalization activities in corporate communication processes. The classification scheme is a relevant contribution for practitioners but also a starting point for further academic research which could provide a better understanding of the different issues during the implementation of personalization activities. Before the 'Classification Scheme of Personalization Constraints' and four 'Standard Types of Personalization Environments' are presented as the final result of this contribution, the approach which led to this results is depicted. At the beginning, a literature review has been conducted. A subsequently applied scientometric approach enhanced the findings of the literature review and served as a supplier of additional insights for the development of the morphological box of personalization. The box was used as an instrument to cover all relevant aspects within the performed case study analysis (minimum and maximum case deviation). The cases were analyzed to generally prove the developed classification scheme and the standard types of personalization as well as to fill possible remaining theoretical gaps within this model.

The structure of the paper starts with a literature review on personalization in general and the definition of 'constraints of personalization activities' in section 2 . It is followed by a 
description of the used methods in section 3 before the results of the research are presented and discussed subsequently in section 4. Section 4 is divided into an overview of the results of the scientometric approach (section 4.1), the morphological box and its description (section 4.2) and the discussion of the findings of the case study research which includes the general description of possible obstacles in personalization activities, an extract of analyzed cases as well as the final results the 'Classification Scheme of Personalization Activities' and the four 'Standard Types of Personalization Environments' (section 4.3). The paper is concluded with the limitations of the study, a summary of the basic findings and an outlook to possible further research.

\section{LiterATURE REVIEW ON PERSONALIZATION}

The literature review on personalization research shows, that it is a very broad topic which spans across different research fields [8-11]. Research questions are ranging from the effective application of recommender systems in computer sciences [12] to the perceived privacy threats in social sciences and business informatics [7]. Extensive research has been conceded to these problem sets, which resulted in very specialized research in every field. Nevertheless, based on these circumstances, personalization research largely fails to provide a commonly agreed general theory. Especially when it comes to the definition of 'personalization', different descriptions have emerged throughout the last years (see Table I).

TABLE I. DEFINITIONS OF PERSONALIZATION

\begin{tabular}{|c|l|}
\hline Source & \multicolumn{1}{c|}{ Definition } \\
\hline$[13]$ & $\begin{array}{l}\text { "Personalization is a process of providing relevant content } \\
\text { based on individual user preferences, and personalized web } \\
\text { sites obtain preferences information implicitly by tracking } \\
\text { customer purchase or usage habits." }\end{array}$ \\
\hline$[14]$ & $\begin{array}{l}\text { "Personalization is a firm's decision on the marketing mix } \\
\text { suitable for the individual that is based on previously } \\
\text { collected customer data." }\end{array}$ \\
\hline$[15]$ & $\begin{array}{l}\text {,Personalization is the adaption of products and services by } \\
\text { the producer for the consumer using information that has } \\
\text { been inferred from the consumer's behavior or transactions." }\end{array}$ \\
\hline
\end{tabular}

Only few contributions are focusing on a general viewpoint on personalization research [8-10] [15-16]. The main findings of their research are for example a distinction between personalization and customization [9], various classification schemes and frameworks of personalization activities [8-10] [17-18] as well as standard types of personalization [8]. A classification scheme which has to be emphasized (see Table II) divides personalization activities in three dimensions: object (what), target (to whom) and origin (who) [8].

The standard types of personalization include an architectural perspective, which aims on the functionality of the web environment; an instrumental perspective, which gives the emphasis on the efficiency and productivity; a relational perspective, that covers social interaction and privacy and a commercial perspective, which intends to increase sales and customer loyalty [8].
TABLE II. ClasSIFICATION Scheme OF PERSONALIZATION [8]

\begin{tabular}{|c|c|c|}
\hline & Implicit & Explicit \\
\hline Content & Individuated Categorical & $\begin{array}{l}\text { Individuated Categorical } \\
\text { Cal }\end{array}$ \\
\hline User Interface & Categorical & $\begin{array}{l}\text { Individuated } \\
\text { Categorical }\end{array}$ \\
\hline $\begin{array}{l}\text { Channel / } \\
\text { Information } \\
\text { Access }\end{array}$ & $\underbrace{\text { Individuated }}_{\text {Categorical }}$ & Categorical \\
\hline Functionality & $\begin{array}{l}\text { Individuated } \\
\text { Categorical }\end{array}$ & $\begin{array}{l}\text { Individuated } \\
\text { Categorical }\end{array}$ \\
\hline
\end{tabular}

Businesses are well advised if they take the different perspectives of personalization activities into consideration. This is especially true if they apply personalization as differentiation strategy, which aims to be a competitive advantage over competitors [5]. The standard types of personalization indicate that there are various types of differentiation when applying personalization activities, ranging from dynamic pricing to an individualized system design. Applying personalization is especially popular in eCommerce environments to attract and retain customers [4] [6]. The communication of individualized messages is seen as an important element of the online marketing mix [19].

But corporations need to handle certain obstacles and constraints when implementing personalization technologies and strategies into their processes. They can be grouped into technological and organizational constraints, in which various subcategories can be found, like judicial or informational obstacles. Although personalization research is a major source of solutions to overcome the mentioned difficulties, a general definition of constraints of personalization activities as well as a general classification of possible constraints is missing. Hence it is necessary to generally define constraints of personalization activities based on the findings about personalization in the literature.

Concluding the discussion, a personalization constraint in corporate communications is every internal or external interference of a business to provide differentiated communication of information based on individual, stated or implied preferences of the customer.

\section{METHODOLODY}

To define the foundations of personalization as a starting point of this study, an extensive literature review has been conducted. Additionally, a scientometric approach was applied to enhance the results and give further insights into popular research topics in personalization and subsequently aid in the development of the morphological box. Therefore, the scientific database 'Scopus' was used to extract the 200 most cited articles published from 2002-2011 (20 from each year) which are related to personalization. The database is part of the SciVerse Platform and provides access to the titles and abstracts of publications in high-ranked journals in the research field. Naturally, not all relevant journals are included in a single database. Nevertheless, due to the reason, that the detection of the most discussed issues in personalization activities of corporations is the aim of the approach, and the 
database gives an overview about personalization topics, the provided dataset seems to be sufficient. Subsequently, different parameters and characteristics of personalization were found by introducing a morphological box [20]. Based on these findings, a general model of personalization constraints, a 'Classification Scheme of Personalization Constraints' and four 'Standard Types of Personalization Environments' were developed which served as the underlying hypothesis of the study.

To prove the developed models or theory respectively, a multi case study analysis was conducted based on the methodological approach of [21] and [22]. The general aim of case study research is to 'expand and generalize' the developed theory by an analytic generalization [21]. This approach is especially advantageous when a complex and dynamic field is examined and if a theory is derived from the analyzed cases [22], which both seems true for the research area in focus. Similar approaches already led to significant developments in other scientific areas [23]. To cover all relevant aspects of personalization by the multi case study approach, a list of cases was set up which was balanced based on the different parameters of the morphological box (minimum and maximum case deviation).

Afterwards, the structure of the individual case reports was defined. They include a general description of the case, a classification of the case by means of the morphological box, a detailed list and description of the found personalization constraints as well as a classification of the case based on the developed theories. Successively, the relevant data from 24 cases was collected and analyzed by applying a web content analysis. Afterwards, the stated theory was adapted to describe the general findings based on the single reports. Subsequently, the single case study report structure was amplified to reflect the adapted theory and the analyzed cases were updated. Finally, a cross case analysis was performed and the additional insights were transformed on the model.

As a result of the gathered data sets several findings can be presented. First, a general differentiation of personalization constraints was developed. Subsequently, a 'Classification scheme of Personalization Constraints' for businesses was proved and finally four 'Standard Types of Personalization Environments' were proposed to enhance the existing personalization theory and aid businesses in successfully identifying possible threats and constraints when planning to apply personalization actions and thus avoid major mistakes in the process.

\section{RESULTS}

\section{A. Recognized Issues in Personalization Research}

As a method to enhance the findings which were retrieved through the conducted literature review, a scientometric approach was used to identify the most relevant and recognized issues in personalization research during the last ten years.

First, the most cited publications of the last ten years were retrieved by using the scientific database 'Scopus'.
In this database, which is a source of leading peerreviewed journals, the term 'personali?ation' was searched. The questionmark was used as a wildcard, which could return results for any applicable character. Due to that approach, the British as well as the US notations of personalization were recognized. The subject area was restricted to 'Computer Science', 'Engineering', 'Social Sciences', 'Mathematics', 'Business, Management and Accounting', 'Decision Sciences', 'Arts and Humanities' and 'Economics, Econometrics and Finance' due to the reason that especially medical articles are not part of the research focus and should be excluded. After retrieving all 5,316 articles in the database related to the relevant part of personalization research, for each of the last ten years (2002-2011), the 20 most cited journal articles were selected. The number of citations ranged from 4 to 288 .

The database provided only abstracts for the selected articles, but this seems sufficient in the light of the research objective due to the reason, that the main findings and issues of an article are provided in the abstract. A content analysis was performed on the 200 most cited abstracts related to personalization. They were exported to the open source content analysis tool 'TagCrowd.com', which was used to highlight the 50 most used terms for each year as well as the 50 most used terms for the whole period. An overview of the outcome is provided in Table III and Table IV.

The results of the introduced scientometric approach on personalization research shows, that - naturally - the user is the focus point of personalization issues. But it is also found, that the retrieval of correct information and data in web environments through learning systems is a frequently addressed topic throughout the last ten years. Personalization research also covers issues related to services and the design of certain systems and products.

Finally it is found, that collaborative filtering approaches, social media contexts, data mining techniques and adaptive systems are used to identify and satisfy the preferences of customers. These results were incorporated into the theory design as well as into the development of the morphological box.

TABLE III. ToP Three ReCOGNIZED TERMs PER YeAR

\begin{tabular}{|c|c|c|c|}
\hline 2011 & model (29) & personalization (28) & learning (25) \\
\hline 2010 & user (53) & systems (32) & tags (27) \\
\hline 2009 & user (68) & personalized (44) & recommendation \\
\hline 2008 & user (51) & learning (28)
\end{tabular}


TABLE IV. Most ReCOGNIZED TERMS 2002-2011

\begin{tabular}{|c|c|c|c|c|}
\hline user (305) & $\begin{array}{c}\text { personali- } \\
\text { zation }(245)\end{array}$ & $\begin{array}{l}\text { informa- } \\
\text { tion (185) }\end{array}$ & web (169) & $\begin{array}{c}\text { learning } \\
(161)\end{array}$ \\
\hline results (152) & systems (152) & $\begin{array}{l}\text { based } \\
(129)\end{array}$ & paper (114) & $\begin{array}{l}\text { recommend- } \\
\text { dation (113) }\end{array}$ \\
\hline search (112) & data (111) & $\begin{array}{l}\text { model } \\
(111)\end{array}$ & $\begin{array}{c}\text { research } \\
(107)\end{array}$ & $\begin{array}{c}\text { approach } \\
\text { (104) }\end{array}$ \\
\hline $\begin{array}{c}\text { services } \\
(102)\end{array}$ & study (95) & $\begin{array}{l}\text { interests } \\
(89)\end{array}$ & design (88) & $\begin{array}{l}\text { algorithm } \\
\text { (82) }\end{array}$ \\
\hline present (82) & query (82) & $\begin{array}{l}\text { different } \\
(81)\end{array}$ & provide (77) & $\begin{array}{l}\text { techniques } \\
\text { (76) }\end{array}$ \\
\hline used (73) & $\begin{array}{c}\text { collaborative } \\
\text { (72) }\end{array}$ & $\begin{array}{c}\text { content } \\
(69)\end{array}$ & $\begin{array}{c}\text { applications } \\
\text { (67) }\end{array}$ & $\begin{array}{c}\text { knowledge } \\
\text { (66) }\end{array}$ \\
\hline $\begin{array}{c}\text { preferences } \\
(66)\end{array}$ & items (64) & $\begin{array}{c}\text { analysis } \\
(62)\end{array}$ & $\begin{array}{c}\text { effective } \\
\text { (61) }\end{array}$ & $\begin{array}{l}\text { important } \\
\text { (61) }\end{array}$ \\
\hline social (61) & $\begin{array}{c}\text { customers } \\
(60)\end{array}$ & trust (60) & $\begin{array}{c}\text { framework } \\
\text { (59) }\end{array}$ & context (58) \\
\hline mining (56) & proposed (53) & $\begin{array}{c}\text { filtering } \\
(51)\end{array}$ & online (51) & $\begin{array}{c}\text { consider } \\
(50)\end{array}$ \\
\hline $\begin{array}{c}\text { adaptive } \\
\text { (49) }\end{array}$ & article (49) & $\begin{array}{l}\text { people } \\
\text { (49) }\end{array}$ & process (48) & $\begin{array}{l}\text { improving } \\
(47)\end{array}$ \\
\hline
\end{tabular}

\section{B. Results And Description Of The Morphological Box}

After defining the relevant and popular topics in personalization research, the 'Morphological Box of Personalization' was developed to enhance the output of the following case study analysis and aid the choice of observed cases (see Table V). The morphological box is recognized as a creativity method to cover all aspects of a defined issue [20]. At this stage of the study, is has been used to define all relevant parameters of personalization activities and their value to aid the subsequent case studies in depicting the possible obstacles.

By following the chosen classification scheme of personalization activities by [8], the first parameters of the 'Morphological Box of Personalization' were found. As one of the first decisions, the company has to choose which object should be personalized. It can include content, user interface, functionality and channel [8]. These defined parameter values can be enhanced by certain subcategories like for example the personalization of price [15] [24], which is attributable to content personalization.

TABLE V. MORPHOLOGICAL Box OF PERSONALIZATION

\begin{tabular}{|c|c|c|c|c|c|c|c|c|c|}
\hline parameter & \multicolumn{9}{|c|}{ value } \\
\hline object & content & \multicolumn{3}{|c|}{ user interface } & & ionality & & \multicolumn{2}{|c|}{ channel } \\
\hline target & \multicolumn{4}{|c|}{ individual (1:1) } & \multicolumn{5}{|c|}{ categorical (1:n) } \\
\hline origin & \multicolumn{4}{|c|}{ user-driven (explicit) } & \multicolumn{5}{|c|}{ company-driven (implicit) } \\
\hline motive & cognitive & \multicolumn{3}{|c|}{ affective } & & & \multicolumn{3}{|c|}{ self-expression } \\
\hline strategy & $\begin{array}{c}\text { individ- } \\
\text { ualization }\end{array}$ & \multicolumn{3}{|c|}{ utilization } & \multicolumn{3}{|c|}{ segmentation } & & $\begin{array}{l}\text { diatio } \\
\mathrm{n}\end{array}$ \\
\hline focus & \multicolumn{4}{|c|}{ person-related } & \multicolumn{5}{|c|}{ context-related } \\
\hline media & print & $\mathrm{rac}$ & & TV & & & mol & & other \\
\hline aim & revenue & \multicolumn{2}{|c|}{$\begin{array}{l}\text { response } \\
\text { rate }\end{array}$} & \multicolumn{2}{|c|}{ loyalty } & $\begin{array}{l}\text { satis- } \\
\text { faction }\end{array}$ & & \multicolumn{2}{|c|}{$\begin{array}{c}\text { differen- } \\
\text { tiation }\end{array}$} \\
\hline cost & \multicolumn{2}{|c|}{ transaction cost } & time & & \multicolumn{2}{|c|}{ premium rate } & & ta & other \\
\hline filtering & rule-based & & $\begin{array}{l}\text { ntent- } \\
\text { ased }\end{array}$ & \multicolumn{3}{|c|}{$\begin{array}{l}\text { collaborative } \\
\text { filtering }\end{array}$} & \multicolumn{2}{|c|}{ hybrid } & other \\
\hline
\end{tabular}

Subsequently, the degree [25] or target [8] of personalization needs to be selected. It can either be a specialized personalization of the object for a single individual or a categorical personalization, which targets a classified group of persons. It has to be mentioned, that a more specified personalization is not always efficient [26].

Additionally, a differentiation between user-driven (explicit) and company-driven (implicit) personalization can be stated [8] [27]. The explicit origin of personalization, which builds on self-revealed information of the user includes the identification profile (e.g. name, contact data), the preference profile (self-revealed preferences), the socioeconomic profile (e.g. age, gender), ratings of products, reviews or pages as well as relationships to other users/customers and given reviews and opinions. On the other side, the implicit personalization which is done automatically by an IT-agent or system of the company can include a transaction profile with a transaction log, an interaction profile (click-stream data) or external data like news or the weather report [25] [27-28].

After defining the basic foundations of each personalization activity, the company now has to choose, which motive the personalization activity underlies respectively which value it would like to create for the customer by personalizing its' offerings. In general it is possible to derive four fundamental needs or motives a customer follows when consuming media. Personalization activities should strive to serve the desired needs best. They split into cognitive motives, which include information about products or services, affective motives, which aim on the entertainment needs of the customer, social motives, which enable the customer to communicate with others and motives of self-expression, which assist the customer in constructing his personal self [29-30].

Companies need to visualize the strategy they would like to follow when implementing personalization. Personalization strategies can be divided into individualization, utilization, segmentation and mediation. Individualization strategies aim to provide a best suited and personalized design 'that incorporates the needs and requirements of users' [8] to enhance the quality and functionality. When utilization is chosen, efficiency is assured by using the right channel and media to deliver the information. The segmentation strategy aims on segmenting the relevant market and users into groups and provide them differentiated products, services or information. Finally the mediation strategy ensures the best possible linkage for social interaction between individuals and strives to enable them to expand their personal relationships [8].

Another differentiation in personalization activities is related to the focus, which can be person-related and is therefore in a close relationship to the collected user (transaction) data, or context-related, which aims on targeting the corporate information on the actual context of the customer like time of the day, current position, date or actual activities performed [25].

Personalization activities naturally need underlying media where they are performed on. They could include classic print 
media like newspapers or magazines, radio, TV, the Internet in general like websites or social media, mobile devices or others. For this research purpose, digital environments like the Internet or communication with mobile devices is relevant.

Another important issue is the aim of the personalization activity. They can be aimed on growing revenue in general or on improving the response rate of customers. But activities could also be directed on the customer loyalty or the customer satisfaction. Finally by doing a personalization activity, also differentiation of the offered product, service, information or the company itself could be an aim [11].

It is also important to depict the costs of the activity for the user. They can include simple transaction costs like e.g. for the access to the Internet. If data is provided by customers, they naturally need time to complete questionnaires or to state their preferences. The submission of additional data, which could be necessary for some personalization activities, implies data security costs. In some cases, customers are charged premium rates for personalization. Other costs are also conceivable [11].

Finally, there is also a difference in the filtering which is applied when personalization activities are performed. First, rule-based filtering for relevant information could be employed, which generates results based on static rules which could be related to all aspects of the user profile like historical transactions or demographic data or to a certain user choice [6]. Also content-based filtering [16] [25] could be applied, which lays the focus on the information which should be provided. Collaborative filtering methods take the preferences, transactions and ratings of other users for the provision of relevant information to the customer into consideration [1516] [25]. Hybrid forms of filtering are also available, which combine different filtering approaches [16]. And finally, there are other approaches too, which include for example web usage mining methods [31].

\section{Case Study Analysis}

As a result of the case study analysis, different types of personalization constraints are introduced. In general, they can be grouped into internal and external constraints.

Internal constraints of personalization activities assemble all types of obstacles that are based on business-internal issues, which detain the corporation from successfully implementing a personalization activity. They can include technological issues like the inability to deploy a certain personalization system or organizational constraints like e.g. that the general characteristics of the sold product or service are not efficiently personalizeable.

External constraints of personalization activities on the other hand gather issues which are not lying in the inability of the company, but the customer or other external institutions or individuals. Examples are statutory rules about the usage of personal data for personalization activities or the attitude of a customer about the provision of individual preferences for a certain application.
There are several classes of personalization constraints that can be drawn. Inside these classes, the specific constraints are loosely related to the steps in the personalization process proposed by [11] and [16]. On the one hand there are technological constraints, which are divided into technological constraints of data collection, technological constraints of matchmaking and technological constraints of delivery. Technological constraints of data collection arise when a data collection system is not able to retrieve the data needed to provide a sufficient personalization base. When the matchmaking system is not able to identify the best information, products or services because it is not able match the offerings with the preferences of the customer, technological constraints of matchmaking occur. Finally, if it is technically not possible to deliver or present the results respectively the design which fits the needs and preferences of the customer, technological constraints of presentation happen.

On the other hand, organizational constraints of personalization activities arise. They include organizational constraints of data collection, organizational constraints of matchmaking as well as organizational constraints of delivery. Data collection could for example be limited by data privacy issues or by the circumstance that not all of the data which has been retrieved from the customer is useful for personalization activities. Matchmaking constraints include the inability to find a suitable product or service which fits the needs of the customer because for example the company does not offer a product variation which applies to the customers' preferences. Finally organizational constraints of delivery are found if for example, the timing of the result presentation does not meet the customers' ability to receive a marketing message.

The following list (see Table VI) includes examples of analyzed cases where businesses have successfully implemented personalization activities. The list contains all cases which are used in the 'Classification Scheme of Personalization' as examples to depict certain classes of personalization constraints. Most of the cases showed more than one limitation in applying personalization activities but the use of each case in the classification scheme was restricted to one to overcome redundancy and provide as much insight into the case study analysis as possible.

\section{TABLE VI. EXAMPLES Of ANALYZED CASES}

\begin{tabular}{|c|c|l|l|}
\hline No. & Case & \multicolumn{1}{|c|}{ Constraint } & \multicolumn{1}{c|}{ Description } \\
\hline 1 & Amazon & $\begin{array}{l}\text { Internal } \\
\text { technological of } \\
\text { matchmaking }\end{array}$ & $\begin{array}{l}\text { Recommends products based } \\
\text { on transactions and other } \\
\text { data }\end{array}$ \\
\hline 3 & Netflix & $\begin{array}{l}\text { External } \\
\text { organizational of } \\
\text { delivery }\end{array}$ & $\begin{array}{l}\text { Recommends films based on } \\
\text { transactions and other data }\end{array}$ \\
\hline 5 & Pandora & $\begin{array}{l}\text { External } \\
\text { technological of } \\
\text { matchmaking }\end{array}$ & $\begin{array}{l}\text { Recommends music songs } \\
\text { based on users' music taste }\end{array}$ \\
\hline 12 & Foursquare & $\begin{array}{l}\text { External } \\
\text { technological of } \\
\text { delivery }\end{array}$ & $\begin{array}{l}\text { Provides personalized } \\
\text { services (flight status) for } \\
\text { booked flights }\end{array}$ \\
\hline 14 & Southwest & Internal & $\begin{array}{l}\text { Shows and recommends } \\
\text { 'places' nearby based on } \\
\text { friends' taste }\end{array}$ \\
\hline
\end{tabular}




\begin{tabular}{|c|c|c|c|}
\hline No. & Case & Constraint & Description \\
\hline & Airlines & $\begin{array}{l}\text { organizational of } \\
\text { matchmaking }\end{array}$ & on a defined home airport \\
\hline 16 & $\begin{array}{l}\text { Google } \\
\text { Search }\end{array}$ & $\begin{array}{l}\text { Internal } \\
\text { technological of } \\
\text { data collection }\end{array}$ & $\begin{array}{l}\text { Provides personalized search } \\
\text { results based on prev. } \\
\text { searches }\end{array}$ \\
\hline 17 & $\begin{array}{l}\text { Google } \\
\text { AdSense }\end{array}$ & $\begin{array}{l}\text { External } \\
\text { technological of } \\
\text { data collection }\end{array}$ & $\begin{array}{l}\text { Provides personalized ads } \\
\text { based on users' preferences } \\
\text { and sites }\end{array}$ \\
\hline 18 & $\begin{array}{l}\text { Facebook } \\
\text { Sponsored } \\
\text { Stories }\end{array}$ & $\begin{array}{l}\text { Internal } \\
\text { organizational of } \\
\text { data collection }\end{array}$ & $\begin{array}{l}\text { Adds information of } \\
\text { companies to status reports }\end{array}$ \\
\hline 20 & L’Oréal & $\begin{array}{l}\text { Internal } \\
\text { organizational of } \\
\text { delivery }\end{array}$ & $\begin{array}{l}\text { Personalizes web sites to } \\
\text { provide individual country } \\
\text { information }\end{array}$ \\
\hline 22 & $\begin{array}{l}\text { Erste Group } \\
\quad \text { Bank }\end{array}$ & $\begin{array}{l}\text { External } \\
\text { organizational of } \\
\text { data collection }\end{array}$ & $\begin{array}{l}\text { Provides personalized } \\
\text { banking channels based on } \\
\text { preferences }\end{array}$ \\
\hline 23 & Direktanlage & $\begin{array}{l}\text { Internal } \\
\text { technological of } \\
\text { delivery }\end{array}$ & $\begin{array}{l}\text { Provides different tools } \\
\text { based on customers' choice }\end{array}$ \\
\hline
\end{tabular}

By analyzing the cases, the 'Classification Scheme Personalization Constraints' can be depicted as shown in Table VII. It is divided into three dimensions which are origin (internal, external), subject (technological, organizational) and time (data collection, matchmaking, delivery).

The origin of personalization constraints can be either external or internal. If an internal personalization constraint is discovered, companies are normally able to resolve these issues internally. The management of such constraints is often time consuming and requires specific technological knowhow, but the company has the ability to control the solution. On the other side, external constraints of personalization are based on factors which the company is not able to influence significantly. These barriers include strict regulations in data security or licensing, privacy concerns of customers or the active participations of users.

Subsequently, the subject of the personalization constraint can be divided into technological and organizational. Technological subjects include the development of accurate mathematical recommendation algorithms or the implementation of data collection systems. Organizational constraints on the other side include management issues like the registration of new users, the control of misuse as well as the resolution of timing matters.

Finally, the last dimension of personalization constraints covers the time on which the obstacle occurs. The timedimension is mainly derived from the personalization process [11] [16] and includes data collection, matchmaking and delivery. Constraints of data collection include the inability of a system to gather user data which could be used for personalization issues. Matchmaking constraints refer to problems of the system or the organization to find products, services or results in general which fit the individual needs and preferences of the user. Delivery issues are then personalization constraints which occur during the delivery phase of the results. For example if the user is not able to retrieve his personalized results because of licensing regulations.
TABLE VII. Classification Scheme OF Personalization CONSTRAINTS

\begin{tabular}{|c|c|c|c|c|}
\hline & & $\begin{array}{c}\text { data } \\
\text { collection }\end{array}$ & $\begin{array}{c}\text { match- } \\
\text { making }\end{array}$ & delivery \\
\hline \multirow{2}{*}{ technological } & internal & Case 16 & Case 1 & Case 23 \\
\cline { 2 - 5 } & external & Case 17 & Case 5 & Case 9 \\
\hline \multirow{2}{*}{ organizational } & internal & Case 18 & Case 14 & Case 20 \\
\cline { 2 - 5 } & external & Case 22 & Case 12 & Case 3 \\
\hline
\end{tabular}

After defining the different constraints of personalization activities finally the following 'Standard Types of Personalization Environments' in marketing were derived from the case study analysis (see Table VIII). They are divided by the origin of possible personalization constraints. Within each group, a differentiation between a high and low impact of the constraint on the personalization activity can be made. The four standard types are named 'Risk', 'Performance', 'Dependence' and 'Flow'.

TABLE VIII. STANDARD TyPES OF PERSONALIZATION ENVIRONMENTS

\begin{tabular}{c|c|c|c|}
\multicolumn{2}{c|}{} & \multicolumn{2}{c|}{ external constraints } \\
\cline { 2 - 4 } & high & low \\
\hline \multirow{2}{*}{$\begin{array}{c}\text { internal } \\
\text { constraints }\end{array}$} & high & Risk & Performance \\
\cline { 2 - 4 } & low & Dependence & Flow \\
\hline
\end{tabular}

If a business is conducting personalization activities in the 'Flow' environment, external and internal constraints have a low impact on these activities. One example of this standard type is case no. 14 'Southwest Airlines'. They offer a basic form of personalization by providing special offers to registrated customers based on their chosen home airport. Internal technological constraints are low, because the company only needs to match new offers to the explicit choice and send a message to the customer. Internal organizational constraints lie in the recurring provision of special offers for all available airports. External technological constraints include the availability of the customers' device. External organizational constraints are mainly covering privacy and timing issues. Summarizing the results, businesses which are operating in this environment can easily perform their personalization activities, because they do not face severe obstacles. They should soon end up in a 'flow' where personalization activities are conducted on a regular basis without any serious negative feedback.

In the 'Performance' standard type, businesses are facing high internal constraints, while external constraints on planned personalization activities are low. One conducted case study which could match with this type is case no. 16. Google Search personalizes their search results for each customer by using a vast basket of data. Constraints to this type of personalization are mostly internal technological barriers. Once Google Search developed a suitable algorithm to match individual preferences and search results, they were able to personalize their offerings. External constraints are typically low in this type and also Google Search is not confronted with 
many external barriers except some privacy issues and negative feedback on the constriction of search results. The standard type is named 'Performance' because the individual performance of the company is needed to successfully conduct personalization activities.

'Dependence' is the third standard type and depicts business situations where companies are facing high external constraints of personalization activities but low internal constraints. Foursquare (case no. 12) is one example of this standard type. Foursquare is highly dependent on external help for the provision of the personalization. Users need to overcome their privacy concerns, provide their individual position and add new places to the system. Once these external barriers are overcome is it easily manageable for the company to provide them their very personal results based on their current position. There are thus only limited internal constraints. Due to these reasons, the standard type is named 'Dependence'.

The last type is named 'Risk' because personalization activities in this section are facing high internal as well as high external constraints. One example for a situation where businesses are working in the risk standard type is the banking sector. In case no. 22 (Erste Group Bank) the bank needs to overcome internal constraints like the development of applications for different operating systems of mobile devices, even though this is not their core competence. And they also need to manage external constraints which mainly include privacy concerns of the customers when they are enabled to use new communication channels as well as security issues. This standard type is named risk, because businesses need to work hard to ensure the management of the internal and external obstacles which are related to these personalization activities.

\section{CONCLUSION, LiMitATIONS AND FUTURE RESEARCH}

Beside the development of an overview of popular personalization issues of the last ten years and a 'Morphological Box of Personalization', the 'Classification Scheme of Personalization Constraints' as well as four 'Standard Types of Personalization Environments' have been introduced. The classification scheme is based on three dimensions, namely origin (internal, external), subject (technological, organizational) and time (data collection, matchmaking, delivery). The standard types are named 'Risk', 'Performance', 'Dependence' and 'Flow' and represent four personalization environments where external and internal personalization constraints are either high or low. The results provide a general starting point for businesses to concern themself with possible obstacles when planning personalization activities. They also enhance the existing personalization literature by introducing a general theory of limitations and constraints of personalization activities in digital environments.

Limitations of the study include on the one hand the choice of the scientific database on which the scientometric approach for theory development is based. Naturally, databases are not able to cover all journal titles. On the other hand the used multi case study research approach to verify the proposed model is only able to give an analytical but not statistical generalization of the research issue.

Further research will be conducted to describe the observed limitations and constraints of personalization activities in more detail. Furthermore, a proposition of success factors which lead to the adequate realization of personalization activities needs to be depicted. Finally, the consequences as well as risks and opportunities of personalization activities and their constraints on corporate communication processes as well as marketing will be analyzed and highlighted in future research.

\section{REFERENCES}

[1] P. Schönhagen, ,Gesellschaftliche Kommunikation im Wandel der Geschichte,“ in Medienpsychologie, B. Batinic, and M. Appel, Eds. Heidelberg: Springer, 2008, pp. 46-76.

[2] M. Hilbert, and P. López, "The World's Technological Capacity to Store, Communicate, and Compute Information," Science, vol. 332, no. 6025, pp. 60-65, 2011.

[3] T. Davenport, L. Mule and J. Lucker, "Know What Your Customers Want Before They Do," Harvard Business Review, December 2011.

[4] A. Ansarai, and C. Mela, "E-customization," Journal of Marketing Research, vol. XL, pp. 131-145, 2003.

[5] M. Porter, Competitive advantage: creating and sustaining superior performance. New York: Free Press, 1985.

[6] K. Tam, and S. Ho, "Understanding the Impact of Web Personalization on User Information Processing and Decision Outcomes," MIS Quarterly, vol. 30, no. 4, pp. 865-890, 2006.

[7] D. Lee, J. Ahn, and Y. Bang, "Managing Consumer Privacy Concerns in Personalization," MIS Quarterly, vol. 35, no. 2, pp. 423-444, 2011.

[8] H. Fan, and M.S. Poole, "What Is Personalization? Perspectives on the Design and Implementation of Personalization in Information Systems," Journal of Organizational Computing and Electronic Commerce, vol. 16, no. 3\&4, pp. 179-202, 2006.

[9] A. Sunikka, and J. Bragge, "Applying text-mining to personalization and customization research literature - Who, what and where?," Expert Systems with Applications, vol. 39, no. 11, pp. 10049-10058, 2012.

[10] A. Sunikka, and J. Bragge, "What, Who and Where: Insights into Personalization," Proceedings of the 41st Annual Hawaii International Conference on System Sciences (HICSS 2008), pp. 283-292, 2008.

[11] J. Vesanen, and M. Raulas, "Building Bridges for Personalization: A Process Model for Marketing," Journal of Interactive Marketing, vol. 20, no. 1, pp. 5-20, 2006.

[12] N. Tintarev, and J. Masthoff, "Evaluating the effectiveness of explanations for recommender systems - Methodological issues and empirical studies on the impact of personalization," User Modeling and User-Adapted Interaction, vol. 22, pp. 399-439, 2012.

[13] S. Ho, "The attraction of internet personalization to web users," Electronic Markets, vol. 16, no. 1, pp. 41-50, 2006.

[14] N. Arora, X. Dreze, A. Ghose, J.D. Hess, R. Iyengar, B. Jing, et al., "Putting one-to-one marketing to work: Personalization, customization, and choice," Marketing Letters, vol. 19, no 3-4, pp. 305-321, 2008.

[15] A. Montgomery, and M. Smith, "Prospects of Personalization on the Internet," Journal of Interactive Marketing, vol. 23, no. 2, pp. 130-137, 2009

[16] G. Adomavicius, and A. Tuzhilin, "Personalization Technologies: A Process-Oriented Perspective," Communications of the ACM, vol. 48, no. 10, pp. 83-90, 2005.

[17] K. Kwon, and C. Kim, "How to design personalization in context of customer retention: Who personalizes what and to what extend?," Electronic Commerce Research and Applications, no. 11, pp. 101-116, 2012

[18] G. Miceli, F. Ricotta, and M. Costabile, "Customizing customization: A conceptual framework for interactive personalization," Journal of Interactive Marketing, vol. 21, no. 2, pp. 6-25, 2007. 
[19] K. Kalyanam, and S. McIntyre, "The e-marketing mix: A contribution of the e-tailing wars," Journal of the Academy of Marketing Science, vol. 30, no. 4, pp. 487-499, 2002.

[20] F. Zwicky, Entdecken, Erfinden, Forschen im Morphologischen Weltbild. Munich: Droemer Knaur, 1966.

[21] R. Yin, Case study research. Beverly Hills: Sage Publications, 1984.

[22] K. Eisenhardt, "Building Theories from Case Study Research," The Academy of Management Review, vol. 14, no. 4, pp. 532-550, 1989.

[23] K. Pousttchi, and D. Wiedemann, "A Contribution to Theory Building for Mobile Marketing: Categorizing Mobile Marketing Campaigns through Case Study Research," International Conference on Mobile Business (ICMB), pp. 1-8, 2006.

[24] B. Murthi, and S. Sarkar, "The Role of the Management Sciences in Research on Personalization," Management Science, vol. 49, no. 10, pp. 1344-1362, 2003.

[25] P. Schubert, and M. Koch, "The Power of Personalization: Customer
Collaboration and Virtual Communities," Proceedings of the 8th Americas Conference on Information Systems, pp. 1953-1965, 2002.

[26] K. Kwon, J. Cho, and Y. Park, "How to best characterize the personalization construct for e-services," Expert Systems with Applications, vol. 37, pp. 2232-2240, 2010.

[27] P. Schubert, Virtuelle Transaktionsgemeinschaften im Electronic Commerce: Management, Marketing und soziale Umwelt. Cologne: Josef Eul, 1999.

[28] K. Riemer, and F. Brüggemann, „Personalisierung der Internetsuche Lösungstechniken und Marktüberblick," Wirtschaftsinformatik, vol. 49, no. 2 pp. 116-126, 2007.

[29] M. Kunczik, and A. Zipfel, Publizistik: Ein Studienhandbuch. Stuttgart: UTB, 2005.

[30] W. Schweiger, Theorien der Mediennutzung. Wiesbaden: VS, 2007.

[31] R. Baraglia, and F. Silvestri, "Dynamic Personalization of Web Sites Without User Intervention," Communications of the ACM, vol. 50, no. 2, pp. 63-67, 2007. 